\title{
REESTRUTURAÇÃO PRODUTIVA NO BRASIL: UM BALAN ÇO CRÍTICO INTRODUTÓRIO DA PRODUÇÃO BIBLIOGRÁFICA
}

\author{
Paulo Sergio Tumolo*
}

\begin{abstract}
RESU M 0: 0 texto apresentaosresultados de uma pesquisa bibliográfica acerca da reestruturação produtiva no Brasil, abrangendo as mais diversas áreas do conhecimento correlatas- sociologia do trabal ho, economia do trabalho, economia política, administração de empresas, educação e trabalho, engenharia. Com esta base, procura apreender, apesar detodos os limites, como vem se conformando tal fenômeno nestepaís eaponta que, no contexto do novo padrão deacumulação decapital, sua principal característica é a intensificação da exploração sobre a força de trabal ho. Ao mesmo tempo, empreendeumaanálise críticada referida bibliografia, buscando indicar seus limites explicativos.

Palavras chave: Reestruturação produtiva; N ovo padrão deacumulação: D egradação do trabalho; Intensificação da exploração; Revisão bibliográfica.
\end{abstract}

N os últimos anos, o mercado bibliográfico tem sido inundado por uma literatura abundante a respeito das profundas transformações produtivas que vêm ocorrendo em escala global. Enquanto alguns anunciam suas virtudes, outros, por sua vez, denunciam suas mazelas. Fala-se no advento de novos padrões produtivos e, sem dúvida, o chamado "modelo japonês" seconverteu numa das principais referências teórico-práticas até meados dos anos 90 . Contudo, é preciso reconhecer que, por diversos motivos, a conformação desse fenômeno no Brasil ainda é insatisfatoriamente conhecida.

Por esta razão, realizei uma pesquisa bi bliográfica de largo alcance com a finalidade demontar um painel da produção investigativa a respeito

* Professor do Centro de Ciências da Educação e do Programa de Pós-G raduação em Educação da U niversidade Federal de Santa C atarina e coordenador do G rupo de T rabal ho "T rabal ho e Educação" da Anped (Associação N acional de Pós-Graduação e Pesquisa em Educação). Email: tumolo@matrix.com.br 
da reestruturação produtiva no Brasil e, dessa forma, buscar apreender, a despeito de todos os limites, como vem se conformando tal fenômeno neste país e, ao mesmo tempo, empreender uma análise crítica da referida bibliografia.

O levantamento bibliográfico atingiu um universo de aproximadamente duas centenas de títulos, abrangendo as mais diversas áreas do conhecimento correlatas: sociologia, notadamente a sociologia do trabaIho, economia do trabal ho, economia política, administração de empresas, educação e trabal ho, engenharia. A amostra selecionada para leitura e análise atingiu cerca de uma centena de textos ${ }^{1}$ e foi feita de acordo com os seguintes critérios: pertinência e consistência do conteúdo e representatividade das várias áreas do conhecimento.

Analisar o processo de reestruturação produtiva no Brasil é uma tarefa difícil e de grande envergadura. Primeiramente, porque este é um fenômeno relativamente novo. De fato, Gitahy (1994, p. 123) afirma que "a difusão de inovações tecnológicas e organizacionais na indústria brasileira começa em meados dos anos 70". Em segundo lugar, e pela razão já apontada, porque os estudos a respeito do processo de trabalho no Brasil ${ }^{2}$ e, principalmente, do processo de reestruturação produtiva também são recentes. Para Catani (1995), nos anos 60 surgiram os primeiros trabal hos críticos e somente na década de 1980 "observa-se a rápida proliferação de pesquisas sobre o processo de trabalho produzidas por sociólogos, mas também por economistas, engenheirosehistoriadores" (idem, p. 25). ${ }^{3}$

Por último, por causa das características próprias tanto do processo de reestruturação produtiva quanto dos estudos que dele se fazem. A esse respeito, assim se manifesta Catani (op. cit., p. 11):

C omo ocorre em outras áreas, a compreensão de um determinado fenômeno é dificultada por dois tipos de problemas. 0 primeiro diz respeito à complexidadeintrínseca do objeto de conhecimento que, no caso do Processo deT rabalho edas $\mathrm{N}$ ovas T ecnologias, éimenso devido à rapidez eà diversidade das mudanças. 0 segundo problema concerne à dispersão de fontes e sua social ização limitada. O s dados e os estudos não só são escassos, como também aqueles existentes não são facilmente encontráveis. Esforços de anos são materializados em relatórios, dissertações eteses que permanecem en gavetados ou acessíveisa poucos. Artigos importantes são publicados em inencontráveis periódicos, análises einformações preciosas permanecem dispersas num semnúmero de publicações. 
Ciente das dificuldades acima enunciadas, fiz a pesquisa bibliográfica ${ }^{4}$ que, em razão de inúmeros limites, não poderá ser apresentada no seu todo neste texto. 0 objetivo é expor, em forma de tópicos, as conclusões e ao mesmo tempo fazer uma avaliação crítica da referida produção bibliográfica. É o que se segue.

- O s resultados das pesquisas apontam que, sob diversos aspectos, o único consenso éo "dissenso". Em outras pal avras, não épossível encontrar, pelo menos dentro dos parâmetros teórico-metodológicos dos referidos estudiosos, nenhuma homogeneidade e nenhum padrão único ou mesmo determinante no que se refere a vários aspectos dos processos de trabalho: introdução de novas tecnologias, organização e gestão do trabalho, qualificação/desqualificação da força de trabalho etc. Tendo como base as pesquisas realizadas, é possível afirmar que a marca distintiva do chamado processo de reestruturação produtiva no Brasil é a "heterogeneidade generalizada", que ocorre não só entre as empresas, mas também no interior delas. Por esta razão parece difícil estabelecer comparações e conexões entre as diversas partes díspares desse mosaico.

- No que diz respeito às relações de trabalho e às relações com as organizações sindicais, constata-se, ao contrário, uma "congruência". Praticamentetodas as pesquisas que as tinham como objeto de investigação apontam a ocorrência da intensificação do ritmo de trabal ho eda diminuição dos postos de trabal ho e, ao mesmo tempo, um empenho das empresas no sentido de afastar e neutralizar a ação sindical, valendo-se de diversos mecanismos, desde a proposta de participação controlada dos trabalhadores até a perseguição e mesmo a demissão sumária dos ativistas sindicais. Algumas pesquisas indicam, também, uma tendência de diminuição do preço do salário.

- M esmo se referindo a fenômenos iguais ou similares, os pesquisadorestêm variadas interpretaçõese, por isso, não extraem, necessariamente, conclusões semel hantes.

- D e uma maneira geral, a utilização de processos de trabal ho tão diversificados tem surtido bons resultados para as empresas em termos de produtividade e competitividade. 
- A quase totalidade das pesquisas foi real izada por meio de estudos de caso, em uma e às vezes em um grupo de empresas, cujos resultados são apresentados em textos que, em sua maioria, não passam de relatos descritivos dos processos de transformação por que passam as empresas pesquisadas e, via de regra, não empreendem análises de maior fôlego. ${ }^{5}$

- Q Q uanto à posiçãa dos autores em rel ação aos processos de reestruturação, é possível detectar, grosso modo, três posturas: um grupo que simplesmente descreve os processos e não manifesta nenhuma posição; outro, de pequeno porte, que se declara favorável e, geralmente, tem uma visão entusiasta; e, finalmente, um conjunto de pesquisadores quetece críticas- nem sempreconcordantes entresi - sobre vários aspectos da reestruturação produtiva em curso no Brasil e, por conseguinte, manifesta desejo de que ela seja diferente, beneficiando a todos, sentimento este que, em geral, vem expresso nos últimos parágrafos de seus textos. D essa forma, tendo uma postura crítica, boa parte dos autores deste último grupo considera que, no Brasil, configura-se um processo de "modernização conservadora".

- É possível averiguar que tanto as pesquisas quanto as análises dos estudiosos ficaram "circunscritas aos processos de trabal ho". M esmo os autores que buscaram fazer uma discussão um pouco mais elaborada e até aqueles que ousaram levantar críticas - a maioria deles - o fizeram dentro desse mesmo parâmetro.

Esse diagnóstico, pelo menos em vários aspectos, écompartilhado por vários estudiosos que vêm se debruçando e buscando analisar a produção bibliográfica - ou parte dela - acerca da temática em voga.

Ferretti et al. (1994), organizadores do seminário "T rabalho e Educação", realizado em 1992,, com a participação de reconhecidos pesquisadores de diversas áreas, afirmam que um dos principais consensos entre os textos apresentados, amplamente ancorado em resultados empíricos, foi "a constatação da existência de uma enorme heterogeneidade de situaç̃̃es na implementação de processos de modernização" (idem, p. 9). Asseveram ainda que,

no B rasil, na opinião de diversos autores, o queestaria acontecen do mesmo seria a ampliação do lequedeheterogeneidadedajá diversificada estrutura produtiva brasileira, herdada da superposição de modelos diferentes, superposição essa 
intensificada a partir da década de 1950. Seria, em outros termos, uma "nova" heterogeneidade que estaria se sobrepondo à já existente. (Idem, p. 10)

T alvez seja por causa disso, vale dizer, da nova heterogeneidade que se sobrepõe à vel ha, que um dos comentadores do referido seminário chega a afirmar que, "no caso do Brasil, vimos nos últimos anos muito mais um processo de desestruturação do que propriamente de reestruturação" (O liveira, 1994, p. 214).

Em entrevista à revista T rabalho \& Educação, T rein (1996), na época coordenadora do GT "T rabalho e Educação" da Anped (Associação $\mathrm{N}$ acional de Pós-G raduação e Pesquisa em Educação), faz um balanço acerca da produção investigativa do referido G rupo de T rabal ho e, ao comentar as temáticas em ascensão e refluxo no interior do GT, afirma que

temas que envolvem abordagens macroeconômicas e políticas em face da crise dos projetos gestados no ideário da modernidade são relegados a segundo plano. Penso que por falta de paciência histórica, estamos nos perdendo no imediatismo, no afã de resultados pal páveis, vendo a árvore e pensando estar vendo a floresta. (Idem, p. 35)

Analisando a literatura sobre o processo de reestruturação no mundo, G itahy (1992) observa que os resultados empíricos de estudos sobre os impactos da introdução de tecnologias microeletrônicas "apontam para um conjunto de efeitos heterogêneos econtraditórios que dependem do caráter não linear do processo de mudança tecnológica, e de sua articulação com a sociedade onde se verificam" (G itahy, 1992, p. 15, grifo meu). M esmo assim, a autora busca identificar al gumas tendências mais gerais, pelo menos no que diz respeito às indústrias de série, que podem ser resumidas nos itens seguintes:

1. No que se refere ao emprego, a tendência é no sentido da redução dos postos de trabalho;

2. verifica-se uma grande alteração na estrutura de qualificações; e

3. mudança do padrão de gestão ou das formas de uso e controle da força de trabalho (idem, p. 16).

Em relação ao Brasil, defendendo a posição segundo a qual se delineia um novo paradigma produtivo, Gitahy (1992) reconhece que "a discussão, tanto no que se refere à natureza do novo modelo, como o seu grau de difusão e quanto às suas implicações sociais, está longe de contar com o consenso dos estudiosos" (idem, p. 19), pois poder-se ia apresentar uma lista de pesquisas 
que apontam para a existência de um grande número de empresas dos mais diversos tamanhos, setores e regiões em processo de reestruturação inspirados principalmente no modelo japonês. Como contrapartida, provavelmente poderíamos listar outro grandenúmero de pesquisas, descrevendo a hegemonia do taylorismo-fordismo nas empresas estudadas. (Idem, p. 58)

Pelo menos neste aspecto, Catani (1995) está de acordo com Gitahy. $\mathrm{N}$ a condição de coordenador de uma das mais completas pesquisas bibliográficas a respeito dos processos de trabal ho e das novas tecnologias, ${ }^{7}$ o autor observa que a extraordinária produção sobre 0 processo de trabalho no Brasil ao longo da década de 80, com ênfases variadas, aponta para o caráter contraditório da inovação tecnológica, num quadro de relações de trabalho conservadoras e de movimento sindical sob tutela do Estado. 0 que transparece nos resultados da pesquisa éque as transformações são feitas de forma irregular e contingente e que 0 controle capitalista raramente é ameaçado. 0 despotismo permanece mesmo naquelas situações de aparente transformação do paradigma fordista (Carvalho, 1990). 0 aperfeiçoamento das relações de trabalho foi parcialmente atingido apenas nas empresas nas quais os sindicatos são fortes e conseguem desenvolver ações autônomas. Para a década de 90, essas conclusões precisam ser revistas. A pesar da crise, a economia brasileira tem revelado um surpreendente dinamismo. $M$ ais do que a introdução de novas tecnologias físicas, o que se observa é a acelerada adoção de tecnologias de gestão. D eforma criativa, o empresariado tem adaptado as diferentes estratégias de organização, compondo um heterogêneo, caótico, porém efetivo "paradigma de flexibilização". Por contraditório que possa parecer e sem configurar uma mítica polarização, o reforço do fordismo (C arvalho, 1990) é concomitante à extensão de técnicas japonesas e às demais novidades "humanistas", holistas, T eoria Y, GSA, e, mais recentemente, às múltiplas facetas da reengenharia (idem, p. 26). Para ele,

os resultados dessa convivência são bastanteclaros: segmentação ediversificação dos trabalhadores e ampliação limitada e seletiva do mercado de trabalho. Em resumo, desigualdade crescente, mesmo com uma possível retomada do crescimento econômico. (Idem, p. 26-27)

Com relação às características da referidaliteratura, $C$ atani constata que, de um modo geral, as pesquisas são baseadas em estudos de caso, 0 que acarreta alguns problemas, tendo em vista que

os dados são habitualmente dispersos e não-comparáveis. Estudos de caso, por vezes, esgotam-se em si mesmos. ${ }^{8}$ O s exemplos internacionais não podem ser transpostos para o caso brasileiro. A rapidez das mudanças e a fal ta de levanta- 
mentos estatísticos confiáveis dificultam as análises maisamplas. (C atani, 1995, p. 10$)^{9}$

M esmo reconhecendo que a estratégia dos estudos de caso é o caminho necessário para fundamentar estudos mais abrangentes, e que os dados e as informações já disponíveis sejam insuficientes, o autor afirma que "deve haver um esforço de análise que dêconta das tendências gerais ou, pelo menos, que defina melhor a articulação dos casos i solados com os processos gerais" (idem, p. 29). Indo na mesma direção einsistindo nesse ponto, Rattner (1994) afirma que

não pesquisamos apenas para acrescentar maisum ponto às evidênciasempíricas já existentes. Em certos momentos, há necessidade de se fazer uma espécie de resumo eperguntar o quea sociedadefará com esses resultados. I sto, meparece, não pode ser inferido apenas a partir das descrições. É necessário também fazer algumas inferências e deduções e, se não for possível tirar conclusões, pelo menos fazer projeções ou extrapolações dessas tendências, para nos situarmos dentro do processo histórico. (Rattner, 1994, p. 81, grifo meu)

Por essa razão, depois de fazer uma avaliação da produção investigativa acerca dos processos de trabal ho e das novas tecnologias e demonstrar seus contornos e limites, Catani faz um alerta, asseverando que

o mundo do trabalho precisa ser sacudido por uma teoria crítica radical. Repetem-se ad infinitum estudos que, embora bem-intencionados, ficam na superfície dos fatos, na revelação do óbvio ou na ambigüidade dos balan ços dos aspectospositivos enegativos sem posicionamentos mais explícitos. 0 exemplo mais flagrante desse desperdício de esforços são as análises sobre a relação tecnologia-emprego esobrea qualificação-desqual ificação da força detrabalho. Baseados em estudo de caso, inúmeros autores progressistas se iludem sobre as reais tendências do capitalismo, pois tomam dados isolados que não revelam a lógica inexorável. 0 capitalismo não gera empregos suficientes e, menos ainda, promoveaqual ificação generalizada. Essesnão são seus objetivose só se real izam em circunstâncias ocasionais, para aten der necessidades pontuais da reprodução. (C atani, 1995, p. 38, grifo meu)

\section{Esboço de análise crítica}

U ma teoria crítica radical, conforme reivindica $C$ atani, pode começar a ser esboçada a partir de uma análise crítica das pesquisas que têm sido realizadas no Brasil que busque evidenciar os limites explicativos dos referenciais teórico-metodológicos utilizados pelos diversos investigadores, com relação à real idade que se vem constituindo. 0 bservando 0 
conjunto de pesquisas que tem estudado o processo de reestruturação produtiva no Brasil, tem-se a impressão, se olharmos numa perspectiva geral e panorâmica, que se configura uma situação caótica - daí, provavelmente, o comentário já enunciado de que parece muito mais um processo de desestruturação do que propriamente de reestruturação - , o que praticamente inviabiliza o estabelecimento de relações e parece dificultar sobremaneira a apreensão do referido fenômeno. Por que os empresários têm lançado mão de mecanismos e processos de trabalho tão diversificados entre si e, inclusive no interior das empresas? T rata-se de uma desestruturação produtiva, de uma espécie de desordem ou, ao contrário, de uma determinada ordem? Existiria neste caos, nesta desordem, alguma lógica? Seria possível estabelecer alguma relação entre a heterogeneidade na introdução das inovações tecnológicas e das novas formas de gestão do trabal ho ea homogeneidadeno que se refere à intensificação do ritmo de trabal ho e à tentativa de neutralização da ação sindical, ou isto é apenas uma casualidade? Essas questões não foram objeto privilegiado de discussão da imensa maioria dos autores que pesquisaram as transformações produtivas no Brasil e creio que, no âmbito de seus respectivos aportes teórico-metodológicos, tais questões não poderiam ser satisfatoriamente tratadas, tendo em vista que, via de regra, suas pesquisas circunscreveram-se à análise dos processos de trabalho.

D e fato, em que pese sua reconhecida contribuição, o balanço da produção bibliográfica acerca da reestruturação produtiva no Brasil demonstra que a análise desenvolvida por quase todos os pesquisadores, mesmo os que lhe fazem críticas pontuais, se restringe ao processo de trabalho, não levando na devida consideração os elementos fundantes e, principal mente, as contradições da acumulação capitalista; procedimento similar ao que identifiquei nos estudiosos do chamado modelo japonês (T umolo, 1997a, p. 341). Para que tal limite teórico-político seja superado, torna-se imperioso compreender o processo de reestruturação produtiva no Brasil no bojo do novo padrão de produção capitalista que começa a tomar feição por volta do início nos anos 70.

$\mathrm{N}$ ão cabe aqui uma análise pormenorizada do novo padrão de acumulação de capital. 0 que importa sublinhar é quetal padrão representa não só a busca de superação do modelo keynesiano-fordista, mas, principalmente, a resposta histórica construída pelo capital à crise de superacumulação ${ }^{10}$ que precede o processo recessivo de 1973. N esse sentido, apesar de suas substanciais diferenças, este novo padrão busca alcançar os mesmos objetivos que os precedentes, qual seja, a superação da crise e a decorrente continuidade da acumulação capitalista, sob um 
novo patamar, sobretudo por meio da intensificação da exploração sobre a força de trabalho.

Com relação aos períodos anteriores, é esta mesma tese, em linhas gerais, que está contida nas análises feitas por $M$ arx, especialmente nos capítulos XI a XIII de O Capital (1983), que abrangem desde a cooperação simples até a maquinaria e grande indústria passando pela manufatura, e por Braverman, na sua obra Trabalho ecapital monopolista (1987), que investiga o período taylorista-fordista. N estes reconhecidos textos clássicos, os autores fazem uma análise primorosa acerca do desenvolvimento capitalista, em suas diversas fases, dissecando as formas por intermédio das quais o capital foi se constituindo historicamente e, no seu movimento contraditório, sintetizado pela contradição de classe queé sua contradição fundamental, foi engendrando formas de intensificar a exploração sobre a força de trabalho. N o seu processo de desenvolvimento, o capital tem de lidar com um conjunto de contradições geradas pela articulação de, entre outros, dois elementos básicos: a concorrência intercapitalista e a luta antagônica com a classe trabalhadora.

Por causa da concorrência, que é um elemento inerente a esse modo de produção, os capitalistas - desde os capitalistas individuais até os grandes conglomerados globais - são constrangidos a fazer investimentos proporcionalmente maiores em capital constante em relação ao capital variável, o que diminui o valor unitário das mercadorias produzidas, proporcionando àqueles que primeiramente assim o procedem uma condição favorável, mesmo que momentaneamente, na concorrência do mercado e, ao mesmo tempo, permitindo-Ihes auferir, durante um certo tempo, um lucro extra. Estas condições favoráveis são anuladas tão logo outros capitalistas implementam as mesmas - e até outras inovações, o que gera uma diminuição generalizada do valor unitário das mercadorias e, portanto, de seu valor, neutralizando aquelas vantagens obtidas pel os primeiros. T odavia, o processo se reinicia de forma constante e ininterrupta, o que acaba por gerar uma contradição inerente à acumulação capitalista, qual seja, uma tendência à queda da taxa de lucro, mesmo que a massa de lucro possa até aumentar. T al fenômeno pode ser mais bem apreendido por meio do que se segue:

1. Como a taxa de lucro é resultante da relação entre a mais-valia e a soma do capital constante e variável;

2. Como a mais-valiae, por decorrência, o lucro só podem ser produzidos pela força de trabalho, ou seja, pelo capital variável e nunca pelo capital constante; e 
3. Como há uma necessidade de investimento cada vez maior em capital constante em relação ao capital variável, ou seja, um aumento da composição orgânica do capital; resulta daqui uma queda tendencial da taxa de lucro que, evidentemente, não ocorre de maneira uniforme, e que se constitui como um dos elementos centrais das crises capitalistas. D essa forma, é possível perceber que, se de um lado o aumento da composição orgânica do capital encaminha soluções para os capitalistas no que diz respeito à concorrência intercapitalista, de outro, causa problemas no processo de acumulação do capital, na medida em que provoca uma ten dência de queda da taxa de lucro, cujo desdobramento mais graveéa eclosão das crises cíclicas de superprodução de capital. ${ }^{11}$

Por sua vez, é no processo recessivo, que geralmente se segue às crises, que o capital engendra a solução, mesmo que precária etemporária, para a contradição descrita acima, basicamente por meio da destruição parcial do capital acumulado, vale dizer, tanto capital constante, como variável. D estruição de capital constante significa aumento da capacidade ociosa das empresas, diminuição generalizada do valor e até eliminação de empresas e mercadorias, falência de algumas empresas e absorção destas por outras etc., e destruição de capital variável implica o rebaixamento de salários, aumento da taxa de desemprego e do "exército industrial de reserva", fome, miséria etc., o que propicia uma intensificação da exploração da força de trabalho - que é o principal segredo da retomada do crescimento eda continuidade da acumulação capitalista -, aguçando, assim, a luta antagônica entre as classes sociais fundamentais. A crise de 1972/73 e sua conseqüente recessão podem ser consideradas como um dos exemplos mais importantes no período recente, pois representam não só a solução e, por conseguinte, a continuidade do processo de acumulação em seu movimento cíclico, como também demarcam a crise do modelo fordista-keynesiano - o que não significa, em absoluto, a sua eliminação - e, por esta razão, a necessidade de o capital gestar e construir um novo padrão de acumulação.

O s novos processos de trabal ho que aí começam a se desenvolver, tão em voga na atualidade e cuja expressão mais conhecida foi o chamado modelo japonês, nada mais são do que a forma histórica encontrada pelo capital para implementar o processo de intensificação da exploração, 0 que exige uma constante reposição/recriação/readequação da luta contra a classe trabalhadora, vale dizer, da estratégia burguesa com vistas à hegemonia do capital. Por isso, embora se justifiquem por motivos técnico-econômicos, sua implementação obedece muito maisuma lógica 
político-econômica. N esse sentido, as empresas capitalistas têm procurado implantar os mais variados processos de trabalho - inovações tecnológicas articuladas com novas formas de organização e gestão do trabalho -, inclusive misturando características dos diversos "modelos", com 0 objetivo de intensificar a exploração sobre a força de trabal ho e, ao mesmo tempo, lograr uma vitória política sobre os trabalhadores, na medida em que conseguem conquistar suas mentes e corações, concomitantemente à neutralização e possível destruição de qualquer forma de organização destes, principalmente aquelas de cunho mais combativo. Isso explica porque não tem sido possível encontrar um "padrão produtivo" único ou mesmo uniforme nos vários países capitalistas, nem entre as próprias empresas e nem mesmo no interior delas. $\mathrm{N}$ a verdade, as empresas capitalistas vêm buscando a combinação mais adequada de "modelos produtivos", de acordo com as características de conjuntura - situação do país ou região onde estão instaladas, perfil da força de trabalho, histórico das lutas e formas de organização dos trabalhadores etc. - com o propósito de atingir os objetivos supra-expostos.

Portanto, nesta chamada era da globalização, os diversos processos de trabalho são sempre particulares a determinados países ou regiões, empresas e até seções ou ilhas dentro de empresas e, nesse plano, balizado analiticamente pela categoria de trabalho concreto, não é possível encontrar uma identidade entre eles. Tal identidade só pode ser desvendada no plano da totalidade, quando se considera que os processos de trabalho estão subordinados ao processo de valorização do capital, ou seja, ao processo de produção capitalista, tendo como base as categorias analíticas de trabal ho abstrato e do trabalho produtivo de mais-valia e capital. D essa maneira, se torna compreensível a razão pela qual os capitalistas lançam mão dos mais diversos processos de trabalho, qual seja, encontrar as formas históricas mais adequadas para intensificar a exploração sobre a classe trabalhadora. Esta é a unidade na diversidade dos processos de trabalho. T rata-se, por conseguinte, da ordem do trabalho subordinada à ordem do capital e não da desordem do trabalho como vêm defendendo vários autores. ${ }^{12}$ Sob a ordem do capital, a ordem do trabalho não pode ser outra senão a necessária busca das formas mais eficientes de explorar a classe trabalhadora. Por esta razão, o processo de reestruturação produtiva em curso no Brasil não pode ser caracterizado, conforme vêm fazendo muitos de seus estudiosos, que até têm uma postura crítica, como o de uma modernização conservadora, na suposição de que existiria uma "modernização progressista" em favor dos trabalhadores e do conjunto da sociedade. ${ }^{13} \mathrm{~T}$ ais estudiosos assim o consideram porque suas pesquisas 
evidenciaram quea modernização produtiva no Brasil tem resultado num processo de degradação do trabalho em todos os seus aspectos. O ra, esta é a lógica do trabalho subsumida pela lógica do capital. Toda modernização produtiva do capital tem a finalidade de conservar, preservar e ampliar a acumulação capitalista baseada na exploração da força de trabaIho e, nesta acepção, toda modernização do capital é conservadora. Por isso, não tem consistência a idéia de uma suposta "modernização progressista" no âmbito da ordem do capital. Aliás, tais adjetivos são inapropriados, uma vez que se trata de uma modernização capitalista, sem qual quer adjetivação. Sobre essa questão, ao comentar criticamente o conceito de modernização conservadora utilizado por Leite (1994) e por muitos outros autores, como já foi visto, Rattner (1994) assim se manifesta:

O ra, me parece que todas as modernizações importantes no último século foram conservadoras. Afinal, a modernização do Japão não tinha nada de revolucionária. Era conservadora, no sentido de manter as relações de poder existentes dentro da sociedade. Por sinal, conseguiram isso muito bem. $\mathrm{Da}$ mesma forma, a modernização da estrutura daA Alemanha, iniciada por Bismark, no final do sécul o passado, foi extremamenteconservadora elevou àscontradições que desembocaram no nazismo e na Segunda Guerra M undial. Temos que manter esses aspectos em mentequando discutimos esses problemas porque, se não, deixamos implícito que existiria alguma forma de modernização revolucionária, dentro do marco jurídico-político capitalista, que não se sabe muito bem onde poderia ter ocorrido. (Idem, p. 79, grifo meu)

D essa forma, levando em conta as profundas diferenças e especificidades que guardam entre si, a busca do incremento da exploração da força de trabal ho éo elemento central na constituição histórica das diversas fases do capitalismo, bem como de seus variados padrões de acumulação, desde os seus primórdios, na cooperação simples, até o keynesiano-fordista e o padrão que daí vem se originando.

$\mathrm{N}$ ão obstante, para além do desemprego, que assola também 0 centro do sistema, convertendo-se num dos problemas mais graves da atualidade, e do conjunto de perdas sofridas pelos trabalhadores, uma das principais especificidades do atual padrão de acumulação tem sido a generalização mundial da extração da mais-valia absoluta, inclusive nos países centrais. D esde o período da subsunção real do trabalho ao capital e do advento do imperialismo, que propiciou uma determinada divisão internacional do trabalho, a extração preponderante de mais-valia absoluta foi se circunscrevendo à periferia do sistema, de tal maneira a permitir, nos países centrais, a preponderância da extração de mais-valia relativa. T al quadro se altera com o novo padrão de acumulação, que tem como 
uma de suas características mais marcantes a gl obalização da extração de mais-valia absoluta, o que implica a globalização da superexploração da força de trabalho. ${ }^{14}$

0 resultado mais palpável e hediondo desse processo pode ser medido pela concentração da riqueza produzida mundialmente, o que é uma necessidade e, uma vez que faz parte da lógica da acumulação, significa um êxito para o capital. U ma reportagem da Folha de S. Paulo denuncia que,

desde 1960, quando os ricos ganhavam 30 vezes mais que os pobres, a concentração da renda mundial mais do que dobrou. Em 1994, os $20 \%$ mais ricosabocanharam $86 \%$ detudo o quefoi produzido no mundo. Sua renda era 78 vezes superior à dos $20 \%$ mais pobres. Esse é o lado menos conhecido da globalização. Ano a ano o fosso que separa os incluídos dos excluídos vem aumentando: os ricosficam mais ricos, e os pobres, mais pobres. Em 34 anos, 0 quinhão dos excluídos na economia global minguou de $2,3 \%$ para $1,1 \%$. A concentração chegou ao ponto de o patrimônio conjunto dos raros 447 bilionários que há no mundo ser equivalente à renda somada da metade mais pobre da população mundial - cerca de 2,8 bilhões de pessoas. (Folha de $S$. Paulo, 2/11/97, Especial, p. 12)

N o caso do Brasil, o fenômeno de recrudescimento da exploração da força de trabalho e a decorrente degradação do trabal ho vêm se realizando por meio da combinação de um conjunto de mecanismos. Além das pesquisas já anunciadas anteriormente, várias outras vêm demonstrando, com profusão de dados, a ocorrência de tal fenômeno.

Balizados pela Pesquisa Industrial M ensal (PIM) da Fundação IBGE, Cacciamali \& Bezerra (1997) demonstram que, entre 1990 e 1995, a indústria brasileira

diminuiu em mais deum quarto o pessoal ocupado eas horas pagasna produção. Essa tendência é confirmada por outras fontes de informação, como a Pesquisa M ensal deEmprego (PM E) damesmafundação, quemostraaocupação industrial perdendo participação relativa na estrutura de emprego das seis maiores regiões metropolitanas brasileiras. No período compreendido entre 1985 e 1990, 0 emprego industrial médio foi da ordem de $25 \%$, passando a representar apenas $20 \%$ entre 1991 e 1995. A intensidade dessa mudança difere entre as regiões, atingindo de forma mais direta, como seria de se esperar, as áreas mais industrializadas do País. Em São Paulo, a diminuição do emprego industrial atingiu 7,3\% pontos percentuais no período [...]. (Cacciamali \& Bezerra, 1997, p. 15)

O s autores observam que, a partir de 1992, depois da recessão do Plano Collor, quando caiu a produção industrial ao mesmo tempo em 
que houve uma queda vertiginosa no número de pessoas ocupadas e nas horas pagas, a produção industrial voltou a crescer, "mas o emprego da mão-de-obra, não. N esse caso prevaleceu o uso mais disseminado das inovações que excluem o trabalhador do processo de produção nas fábricas" (idem, p. 31). Por outro lado, enquanto cai acentuadamente o número de empregos, "os ganhos acumulados entre 90 e 95 para a indústria de transformação são cerca de $48 \%$ quando observada a relação entre a produção industrial e o número de horas pagas na produção!" (C acciamali \& Bezerra, 1997, p. 16).

D epois de apreciar os indicadores industriais relacionados à produção e emprego, os autores concluem que "fica clara a correlação entre a evolução da produtividade e a queda do nível de emprego entre 1990 e 1995 para quase todos os gêneros da indústria brasileira" (idem, p. 32).

Analisando e comparando os indicadores da Pesquisa Industrial M ensal de Produção Física (PIM -PF) e da Pesquisa Industrial M ensal $D$ ados $G$ erais (PIM -D G ), ambas do IBGE, e os dados de uma pesquisa do BN D ES, C N I eSebrae, com 1.356 empresas dos mais distintos portes e setores, Salm et al. (1997) chegam à mesma constatação que C acciamali $\&$ Bezerra, tendo em vista que

houve efetivamente forte crescimento da produtividade na primeira metade dos anos 90 e que tal comportamento está associado à introdução de um conjunto amplo de métodos de gestão da produção voltados para 0 aumento da competitividade das empresas. I sso explicaria a convivência de altas taxas de crescimento da produtividade com baixas taxas de investimento em capital fixo. (Salm et al., 1997, p. 52-53)

Com o intuito de contribuir para a identificação e o entendimento da componente tendencial do desemprego aberto no Brasil, ou seja, do desemprego estrutural, Portugal \& Garcia (1997) avaliam os dados da Pesquisa M ensal deEmprego (PM E) do IBG E echegam à conclusão que, "a partir do final da década de 80 e início da década de 90 , existe um aumento do desemprego estrutural no Brasil" (Portugal \& Garcia, 1997, p. 68).

Baltar et al. (1996) fazem um estudo a respeito do mercado de trabalho e da exclusão social no Brasil e demonstram que, a partir dos anos 90 , se configura um quadro macroeconômico que leva as empresas a adotar "políticas defensivas de reestruturação", que tem implicado devastadora eliminação de postos de trabalho. Para eles,

o padrão de desenvolvimento pós-30, fundado no processo deindustrial ização e em condições políticas muito particulares, gerou uma sociedadeheterogênea, 
ondea pobreza ea exclusão social eram frutos do não enfrentamento do problema agrário e da reprodução de uma força de trabalho mal remunerada. A crise daquelemodelo de desenvolvimento e, mais recentemente, das políticas liberais adotadas tem feito emergir uma nova forma de pobreza, que tem como foco a expulsão demassas detrabal hadores dos segmentos industriaisenão-industriais urbanos mais estruturados. (Baltar et al., 1996, p. 106)

Baseados nos dados da Relação Anual de Informações Sociais (RAIS) do estado de São Paulo, Baltar \& Proni (1996) fazem uma análise da rotatividade da mão-de-obra e da estrutura salarial do emprego formal e descobrem que, ao contrário do que se vem afirmando, as relações de trabalho se caracterizam pela flexibilidade e não pela rigidez, tendo em vista que, para grande parte do emprego formal, o vínculo de trabalho tem curta duração, transformando o operário brasileiro num trabalhador temporário. Para eles, "na prática, a regulamentação do trabalho no País não garante estabilidade no emprego e permite alta flexibilidade para o empregador contratar, usar, remunerar, edispensar trabalhadores" (idem, 1996), o que acarreta graves efeitos sobre a estrutura salarial e sobre a qualificação da força de trabalho. Segundo os pesquisadores,

desde 1980, o mercado de trabalho no Brasil tem apresentado uma proliferação de empregos fora do círculo dos estabelecimentos organizados e que não envolvem a assinatura da carteira de trabalho. A década de 1990 trouxe um agravamento da situação, na medida em quea abertura da economia favoreceu uma redução absoluta do emprego formal na indústria de transformação e na construção civil. D esse modo, não se trata apenas dos efeitos da estagnação econômica sobreo mercado de trabal ho, mas do começo de uma reestruturação da economia que tem afetado a capacidade de geração de empregos. Essas mudanças, especialmente a diminuição do peso do emprego formal, podem inclusive ser interpretadas como um indício de uma ten dência para uma maior desagregação da estrutura socioeconômica nas regiões mais desenvolvidas do País. (Baltar \& Proni, 1996, p. 141)

M esmo reconhecendo que não se trata de uma comprovação definitiva, a análise acerca da reestruturação produtiva no Brasil sob a égide do capital, com base nas inúmeras pesquisas realizadas, apresenta indícios claros de recrudescimento da degradação do trabal ho no Brasil no final do século 20, como resultado necessário do processo de intensificação da exploração sobre a força de trabalho, que, conforme procurei demonstrar, se configura como característica determinante do novo padrão de acumulação de capital. I sso significa uma tendencial redução nas possibilidades de implementação de propostas alternativas por dentro da ordem 
capitalista e implica, para a classe trabalhadora e para aqueles que com ela se identificam, a necessidade urgente da retomada da luta pela superação desta ordem. Provavelmente, nunca a insígnia marxista foi tão presente e premente: pelo fim do trabalho assalariado!

\section{Recebido para publicação em outubro de 1998. \\ Revisto pelo autor em novembro de 2001.}

\section{$\mathrm{N}$ otas}

1. A relação desses textos está contida na bibliografia, no final deste artigo.

2. Q uanto aos estudos acerca desta temática no mundo, G itahy (1992, p. 13) diz que "é possível afirmar que, após a contribuição dos teóricos clássicos, o debate no início do século e o surto de trabalhos sobre automação durante a década de 50 , o interesse no estudo do processo de trabalho só vai ressurgir a partir do final dos anos 60. Este surto de novos trabalhos cresce ao longo dos anos 70, intensificando-se ao longo dos $80 "$.

3. Referindo-se aos processos de trabalho no Brasil, G itahy (idem, p. 14) afirma que "é só a partir do final dos anos 70 e ao longo dos 80 do século 20 que encontramos a emergência de um número significativo de trabalhos sobre o tema".

4. Ao realizála, pude testemunhar a veracidade ea contundência das dificuldades apontadas por Catani.

5. Isso pode explicar a existência de uma quantidade significativa de pequenos artigos, al guns até com uma página e meia, publicados, inclusive, em revistas reconhecidas em suas respectivas áreas.

6. O s textos do seminário deram origem ao livro N ovas tecnologias, trabalho e educação. U m debate multidisciplinar (Ferretti et al., 1994).

7. 0 autor apresenta uma evolução histórica da produção no âmbito da sociologia do trabalho em diversos países, e sua influência no Brasil. Ver C atani (1995, p. 16 e ss.).

8. 0 autor afirma que "os limites desses trabal hos decorrem da especificidade das empresas e dos processos analisados em setores de ponta, regional mente localizados, e com características não comparáveis com os demais" (Idem, p. 26).

9. 0 autor aponta, ainda, alguns limites, ao averiguar que os pesquisadores têm escolhido determinados setores econômi cos em detrimento de outros, concentrando-se, basicamente, no setor industrial e, nesse, no ramo metal-mecânico.

10. A maioria dos autores a considera como crisedo petróleo, em decorrência do aumento dos preços desteinsumo. Em minha avaliação, embora tenha características particulares quea distinguem de outras, trata-se essencialmente de uma crise típica de superprodução de capital, sendo o choque do petróleo apenas uma de suas manifestações aparentes. A respeito desta questão, veja a análise, fundada em abundância de dados empíricos, desenvolvida por M andel (1990).

11. A respeito dessas intrincadas questões, M arx tece uma minuciosa análise em vários capítulos de 0 Capital (1983). M eu objetivo não é fazer uma análise aprofundada delas, mas, tão somente, trazêlas à tona de forma resumida.

12. A desordem do trabalho éo título e, ao mesmo tempo, a tese central do livro de M attoso (1995). Com pequenas diferenças, é a concepção também partilhada por C ano (1995). 
13. A esse respeito, $C$ atani afirma que "nas suas formas e estratégias 'pós-modernas', o capitalismo apenas confunde 0 cientista social, que vê, nas formas de gestão e na qualificação parcial, avanços que beneficiarão o conjunto da sociedade. Esquece assim que, para se reproduzir, 0 capitalismo necessita da desigualdade, da marginalização e da exclusão. As velhas e novas tecnologias são elementos de diferenciação social, e diferenciação significa desigualdade, fragmentação e fragilidade dos produtores diretos que, assim, podem ser facilmente agenciados para atender aos interesses do capital" (Catani, 1995, p. 38-39).

14. Este é um dos temas mais importantes na análise desenvolvida por $\mathrm{H}$ arvey (op. cit.). Ver, por exemplo, p. 174 e ss.

15. Indo na mesma linha, Santos \& Pochmann (1996) e Santos (1996) comprovam que o custo do trabal ho no Brasil é um dos mais baixos do mundo, e M anzano (1996) demonstra que os dispêndios com a demissão de trabal hadores no Brasil não representam ônus significativos para os empresários.

\title{
Productive Restructuring in BRAZIL: \\ AN INTRODUCTORY CRITICAL REVIEW OF THE BIBLIOGRAPHIC PRODUCTION
}

\begin{abstract}
ABST RACT : Encompassingvariousfiedds of knowledge- sociology of labor, economy of labor, political economy, company administration, education and work and engineering-, thistext presentsthefindings of a bibliographic research on theproductiverestructuring in Brazil. It then seeksto apprehend, despiteall thelimits, how such a phenomenon took placein thecountry and points out that, in the context of thenew order of capital accumulation, its main characteristic istheintensification of thelabor forceexploitation. At the same time, it proposes a critical review of the concerned bibliography, pointing out the limits of its accounts.
\end{abstract}

Key words: Productive restructuring; N ew norms of accumulation; W ork deterioration; Exploitation intensification; Literaturereview.

\section{Referências bibliográficas}

ABRAN CHES, Sérgio et al. "Caminhos da modernização empresarial no Brasil". Projeto M odernização Empresarial e Emprego no Brasil. D ocumento de Trabalho no 2, Finep, out. 1994.

AN T U N ES, Ricardo. Adeus ao trabalho? Ensaio sobre as metamorfoses e a centralidade do mundo do trabalho. São Paulo: Cortez/Editora da U nicamp, 1995.

AN TU N ES J r., José Antonio V alle et al. Considerações críticas sobre a evolução das filosofias de administração da produção: D o 'just-incase' ao 'just-in-time'. Revista de Administração de Empresas, São Paulo, 1989, no 29 (3), p. 49-64. 
A REV O LU ÇÃO queliquidou o emprego. Veja. 19 out. 1994, p. 88-95.

BALTAR, Paulo E. de A.; DEDECCA, Claudio S. \& HENRIQUE, Wilnês. "M ercado de trabal ho e exclusão social no Brasil". In: LIVEIRA, Carlos A.B. \& M at Toso, Jorge E.L. (O rgs.), Crise e trabalho no Brasil. M odernidade ou volta ao passado? São Paulo: Scrittal Página Aberta/C esit, 1996.

BALTAR, Paulo E. de A. \& PRONI, M arcelo W. "Sobre o regime de trabalho no Brasil: Rotatividade da mão-de-obra, emprego formal e estrutura salarial". In: O liveiRA, Carlos A.B. \& M atToso, Jorge E.L. (O rgs.), Crise e trabalho no Brasil. M odernidade ou volta ao passado? São Paulo: Scritta/Página Aberta/C esit, 1996.

BRAVERM AN, H arry. Trabal ho e capital monopolista. A degradação do trabalho no século XX. 3aㅡ ed. Rio de J aneiro: Guanabara, 1987.

BRESCIAN I, Luis P. T ecnologia, organização do trabalho e ação sindical: $D$ a resistência à contratação. D issertação de $M$ estrado, U niversidade Estadual de São Paulo, São Paulo, 1991.

BRESCIANI, Luis P. \& ODA, Nilson T. Reestruturação empresarial, sindicalismo e democratização: Isso dá jogo? Forma \& Conteúdo, 1993, № 5, p. 3-8.

BURAW OY, M ichael. A transformação dos regimes fabris no capitalismo avançado. Revista Brasileira de Ciências Sociais. São Paulo: Anpocs, 1990, vol. 5, no 13, p. 29-50.

CACCIAM ALI, M aria C.\& BEZERRA, Lindemberg deR. "Produtividade e emprego industrial no Brasil". In: Carleial, Liana \& Valle, Rogério (O rgs.), Reestruturação produtiva e mercado de trabalho no Brasil, São Paulo: H ucitec/Abet, 1997.

CAN O, Wilson. Reflexões sobre o Brasil e a nova (des)ordem internacional. 4ae ed. ampl. Campinas: U nicamp/Fapesp, 1995.

CARLEIAL, Liana \& VALLE, Rogério (O rgs.). Reestruturação produtiva e mercado de trabalho no Brasil. São Paulo: H ucitec/A bet, 1997.

CARVALHO, Ruy de Quadros. Programmable Automation and Employment Practices in Brazilian Industry. Tese de D outorado na U niversity of Sussex, 1993. 
. "Capacitação tecnológica, revalorização do trabalho e educação". In.: Ferrettı, C elso J. et al. (O rgs.), N ovas tecnologias, trabaIho e educação: U m debate multidisciplinar, Petrópolis: V ozes, 1994.

.\& SCH M ITZ, H . O Fordismo está vivo no Brasil. N ovos Esudos Cebrap, São Paulo: Cebrap, 1990, no 27, p. 148-156.

CAST RO , M aria Silvia Portella de. "Possíveis estratégias sindicais frente a reestruturação produtiva no Brasil". In: CASTRO, M aria S.P. \& WaCHEND ORFER, Achim (Coords.), Sindicalismo latinoamericano. Entre la renovación y la resignación. Caracas: N ueva Sociedad/ ILDES-FES (Brasil), 1995.

CAST RO , N adya Araujo. Q ualificação, qualidades e classificações. Educação \& Sociedade, C ampinas: C edes/Papirus, 1993, no 45, p. 211224.

. "O rganização do trabal ho, qualificação e controle na indústria moderna". T rabalho e Educação - Coletânea CBE. 2ํed. Campinas: Papirus, 1994.

CASTRO, Nadya \& GUIM ARÃES, A.S. Trabalho, sindicalismo e reconversão industrial no Brasil nos anos 90. Lua N ova, São Paulo, dez. 1990, no 22.

CATAN I, Antonio D avid. Processo de trabalho e novas tecnologias. Porto Alegre: Editora da U FRGS, 1995.

CAT AN I, Antonio D avid (O rg.). T rabalho e tecnologia. D icionário crítiCo. Petrópolis/Porto Alegre: Vozes/Editora da U FRGS, 1997.

CORIAT, Benjamin. Pensar pelo avesso. Rio de Janeiro: U FRJ, 1994.

DEDECCA, Claudio Salvadori. "Racionalização econômica e heterogeneidade nas relações e nos mercados de trabal ho no capitalismo avançado". In: O liveira, Carlos A.B. \& M attoso, Jorge E.L. (O rgs.), Crise e trabalho no Brasil. M odernidade ou volta ao passado? São Paulo: Scritta/Página Aberta/C esit, 1996.

DELGAD O, M aria B. Godinho. "Sindicalismo latino-americano: 0 difícil diálogo entre mulheres e homens". In: CASTRO, M aria S.P. \& W ACHEND ORFER, Achim (Coords.), Sindicalismo latinoamericano. 
Entre la renovación y la resignación. Caracas: N ueva Sociedad/ ILDES-FES (Brasil), 1995.

DEPARTAM EN T O de Estudos Socioeconômicos e Políticos da CUT. Indicadores D esep 94, 1994.

DIEESE. T rabalho e reetruturação produtiva . São Paulo: D ieese, 1994. . Anuário dos Trabalhadores. 1994.

FASE/PT U. Cadernos de Proposta. Crise e Reestruturação Industrial. Rio de Janeiro, 1993, no 1.

FERN AN D ES, Florestan. T ransição difícil para os sindicatos. Folha de São Paulo, 19 jun. 1995.

. Sindicalismo e poder operário. Folha de São Paulo, 12 jun. 1995.

FERRETTI, Celso. J. et al. (O rgs.). N ovas tecnologias, trabalho e educação: U m debate multidisciplinar. Petrópolis: V ozes, 1994.

FID ALGO, Fernando Selmar (O rg.). G estão do trabalho e formação do trabalhador. Belo H orizonte: M ovimento de Cultura M arxista, 1996.

.\& M ACH AD 0, Lucília R. de Souza (O rgs.). Controle da qualidade total: U ma nova pedagogia do capital. Belo H orizonte: M ovimento de Cultura M arxista, 1994.

FLEU RY, Afonso. "N ovas tecnologias, capacitação tecnológica e processo de trabalho: Comparações entre o modelo japonês e o brasileiro". In: H IRATA, H elena (O rg.), Sobre o "modelo" japonês, São Paulo: Edusp, 1993.

.\& H U M PH REY, John (C oords.). Recursos humanos e a difusão e adaptação de novos métodos para a qualidade no Brasil. Braślia: IPEA, 1993, no 326.

FLEU RY, M aria T ereza Leme. "M udanças e persistências no modelo de gestão de pessoal em setores de tecnologia de ponta: 0 caso brasileiro em contraponto". In: H Irata, H elena (O rg.). Sobre o "mode Io" japonês, São Paulo: Edusp, 1993. 
. "A cultura da qualidade ou a qualidade da mudança". In: FerRett।, Celso J. et al. (O rgs.), N ovas tecnologias, trabalho e educação: U m debate multidisciplinar, Petrópolis: V ozes, 1994.

. \& FISCHER, Rosa M aria. Processo e relaçoes do trabalho no B rasil: M ovimento sindical, comissão de fábrica, gestão e participação, o modelo japonês de organização da produção no Brasil (CCQ e Kanban). São Paulo: Atlas, 1992.

FLEU RY, Paulo Fernando. "Ambiente econômico e resposta empresarial: 0 ajuste da indústria brasileira nos anos 90". Policy Paper, Fundação Friedrich Ebert/ILDES, 1996, № 19.

FRAN ZOI, N aira Lisboa. A fábrica vista pelos trabalhadores: D o outro lado da modernidade. Educação \& Sociedade, Campinas: Cedes/ Papirus, 1996, № 56, p. 476-501.

FREEM AN, Richard B. Pueden sobrevivir los sindicatos en la sociedad postindustrial? Simposio Internacional Sobre las Perspectivas Futuras del Sindicalismo, 1986 (mimeo).

GITAHY, Leda. N a direção de um novo paradigma de organização industrial? XVI Encontro Anual da Anpocs - GT "Processo de trabaIho e reivindicações sociais", 1992.

. "Inovação tecnológica, relações interfirmas e mercado de trabaIho". In: (O rg.), Reestruturación productiva, trabajo y educacion en América Latina (Lecturas de educacion y trabajo $\mathrm{n}$-3), Campinas: IG/U nicamp, Buenos Aires, RED CIID -Cenep, 1994.

. \& RABELO, Flávio. Educação e desenvolvimento tecnológico: 0 caso da indústria de autopeças. Educação \& Sociedade, Campinas: Cedes/Papirus, 1993, no 45, p. 225-251.

G lobalização aprofunda o abismo entre ricos e pobres. Folha deS.Paulo, 2 nov. 1997, Especial, p. 12.

GOLDENSTEIN, Gisela T. Trabalho e dominação no capitalismo monopolista: U m esboço de sistematização. Revista de Administração de Empresas. Rio de Janeiro, 1986, no 26 (4), p. 5-17. 
GOUNET, Thomas. 0 toyotismo e as novas técnicas de exploração na empresa capitalista. D ebate Sindical, 1992, no 10, p. 21-25.

H ARVEY, D avid. A condição pós-moderna. São Paulo: Loyola, 1993.

H IRATA, H elena (O rg.). Sobreo "modelo" japonês. São Paulo: Edusp, 1993.

. "D a polarização das qualificações ao modelo da competência". In: Ferrettı, Celso J. et al. ( 0 rgs.), N ovas tecnologias, trabalho e educação: U m debate multidisciplinar. Petrópolis: V ozes, 1994.

H U M PH REY, John. "Adaptando o 'modelo japonês' ao Brasil". In: H IRATA, H elena (O rg.), Sobreo "modelo" japonêe", São Paulo: Edusp, 1993.

JOFFILY, Bernardo. U ma revolução que desafia os sindicatos. D e fato, 1993, ano 1, no2, p. 14-25.

KO N , Anita. A modernização tecnológica brasileira e o ajustamento dos recursos humanos. Revista de Administração de Empresas, São Paulo, 1991, no 31 (4), p. 5-15.

KO N IG, H elmut. "A crise da sociedade do trabal ho e o futuro do trabaIho: C rítica de um debate atual". In: M ARKERT, W erner ( 0 rg.). Te orias de educação do I luminismo, conceitos de trabal ho esujeito, Rio de Janeiro: Tempo Brasileiro, 1994.

KREIN, José D ari. "Reestruturação produtiva e sindicalismo". In: CARLEIAL, Liana \& V ALle, Rogério (O rgs.), Reestruturação produtiva e mercado de trabalho no Brasil. São Paulo: H ucitec/ABET, 1997.

LARAN GEIRA, Sonia M.G. "Inovações tecnológicas e ação sindical: Crise nos sindicatos?" In: D INIZ, Eli; Lopes, José Sergio Leite \& Prandi, Reginaldo (O rgs.), 0 Brasil no rastro da crise, Anpocs/I pea/ H ucitec, 1994.

LEITE, Elenice M . "T rabal ho equalificação: A classe operária vai à escola". In: G IтAнy, Leda (O rg.), Reestruturación productiva, trabajo y educacion en América Latina. (Lecturas de educacion y trabajo $\mathrm{n}$ 3), Campinas, IG/Unicamp, Buenos Aires, RED CllD-Cenep, 1994.

. El rescate de la calificación. M ontevideo: Cinterfor, 1996. 
LEITE, M arcia de Paula. N ovas formas de gestão da mão-de-obra e sistemas participativos: U ma tendência à democratização das relações detrabalho? Educação \& Sociedade, Campinas: Cedes/Papirus, 1993, no 45, p. 190-210.

. "M odernização tecnológica e relações de trabalho". In: FerretTI, Celso J. et al. (O rgs.), N ovas tecnologias, trabalho e educação: Um debate multidisciplinar. Petrópolis: V ozes, 1994.

. "M odernización Tecnológica y calificación". In: GiтAнy, Leda (O rg.), Reestructuración produtiva, trabajo y educación en America Latina. (Lecturas de educacion y trabajo no 4), Campinas: IG / U nicamp, Buenos Aires, RED CIID -Cenep, 1995.

. (O rg.). 0 trabalho em movimento. Reestruturação produtiva e sindicatos no Brasil. Campinas: Papirus, 1997.

.\& RIZEK, CibeleS. Projeto: Reestruturação produtiva e qualificação. Educação \& Sociedade, Campinas: Cedes, 1997, no 58, p. 178-198.

LEO N E, Eugênia T roncoso. "Empobrecimento da população e inserção da mulher no mercado de trabalho na região metropolitana de São Paulo na década de 1980". In: O liveiRA, Carlos A.B. \& M AT T oso, Jorge E.L. (O rgs.), C rise e trabalho no Brasil. M odernidade ou volta ao passado? São Paulo: Scritta/Página A berta/C esit, 1996.

LIED KE, ElidaR \& \& SILVA, LorenaH . da. Inovações na organização do processo de trabalho e relações de gênero. Educação $\&$ Sociedade, Campinas: C edes/Papirus, 1993, no 45, p. 278-296.

LO BO, Elisabeth Souza. "M odelo japonêse práticas brasileiras". In: H IRATA, H elena (O rg.), Sobre o "modelo" japonês São Paulo: Edusp, 1993.

LOPES, Juarez R. Brandão. Reestruturação produtiva, mercado de trabalho e condições de vida. Educação \& Sociedade, Campinas: $\mathrm{Ce}$ des/Papirus, 1993, no 45, p. 180-189.

M ACH AD O, Lucília R. de Souza. "A educação e os desafios das novas tecnologias". In. Ferrettı, C elso J. et al. (O rgs.), N ovas tecnologias, 
trabalho e educação: U m debate multidisciplinar. Petrópolis: V ozes, 1994.

"Q ualificação do trabalho e relações sociais". In: FIDALGo, Fernando Selmar (O rg.). G estão do trabal ho e formaç̧ão do trabalhador. Belo H orizonte: M ovimento de Cultura M arxista, 1996.

M AN DEL, Ernest. A crise do capital: O s fatos e sua interpretação marxista. São Paulo: U nicamp/Ensaio, 1990.

M AN ZAN O, M arcelo P. Ferrari. "C usto de demissão e proteção do emprego no Brasil". In: O liveira, Carlos A.B. \& M attoso, Jorge E.L. (O rgs.), Crise e trabalho no Brasil. M odernidade ou volta ao passado? São Paulo: Scritta/Página Aberta/C esit, 1996.

M ARTIN S, H eloisa de Souza. "O s dilemas do movimento sindical em face da terceirização". In: \& RAM ALH O, José Ricardo (O rgs.), T ercerização: Diversidade e negociação no mundo do trabalho, São Paulo: H ucitec-C edi/N ET S, 1994.

M ART IN S, H eloisa deS. \& RAM ALH O, JoséR. (O rgs.). T erceirização: D iversidadee negociação no mundo do trabalho. São Paulo: H ucitecCedi/N ET S, 1994.

M ARX, Karl. 0 Capital. Vol. I, São Paulo: Abril Cultural, 1983.

.(s.d.). C apítulo VI inédito de 0 Capital. São Paulo: M oraes, 1983a.

MATT OSO, Jorge. A desordem do trabalho. São Paulo: Scritta/Página Aberta, 1995.

. "Emprego e concorrência desregulada: Incertezas e desafios". In: O liveira, Carlos A.B. \& M attoso, Jorge E.L. (O rgs.), Crise e trabalho no Brasil. M odernidade ou volta ao passado? São Paulo: Scritta/Página Aberta/C esit, 1996.

M EI KSIN S, Peter. T rabal ho e capital monopolista para os anos 90: U ma resenha crítica do debate sobre o processo de trabalho. Crítica M arxista, São Paulo: Brasiliense, 1996, vol. 1, no. 3, p. 106-117.

M ÉSZARO S, István. Produção destrutiva e Estado capitalista. São Paulo: Ensaio, 1989. 
MORAES NETO, Benedito Rodrigues de. Automação de base microeletrônica e organização do trabalho na indústria metal-mecânica. Revista de Administração de Empresas. Rio de J aneiro, 1986, no 26 (4), p. 35-40.

N ED ER, Ricardo T oledo. N ovastecnologias eação sindical em São Paulo. N otas de pesquisa. Revista de Administração de Empresas. São Paulo, 1989, no 29 (1), p. 23-33.

N EDER, R.T . et al. Automação emovimento sindical no Brasil. São Paulo: H ucitec, 1988.

NEVES, M agda de Almeida. M odernização industrial no Brasil: 0 surgimento de novos paradigmas na organização do trabalho. Educação \& Sociedade, C ampinas: C edes/Papirus, 1993, no 45, p. 268277.

. "M udanças tecnológicas e organizacionais e os impactos sobre o trabal ho e a qualificação profissional". T rabalho eEducação - Coletânea CBE. 2ํed., Campinas: Papirus, 1994.

O LIVEIRA, Carlos A.B. \& M ATT OSO, Jorge E.L. (O rgs.). Crisee trabalho no Brasil. M odernidade ou volta ao passado? São Paulo: Scrittal Página Aberta/C esit, 1996.

O LIVEIRA, M arco Antonio de. "D ebate". In: Ferretti, Celso J. et al. (O rgs.), N ovas tecnologias, trabalho e educação: U m debate multidisciplinar, Petrópolis: Vozes, 1994.

O SIN DICALISM 0 radical entrou em crise. Jornal do Brasil, 29 maio 1995.

PELIAN O, J osé C arlos. Empresários, trabal hadores e governo: As negociações sobre as novas tecnologias no Brasil. Revista de Administração de Empresas, São Paulo, 1989, no 29 (1), p. 5-22.

PINHEIRO, Ivan A . \& SANTOS, João M. "As opiniões de alguns sindicalistas ante as mudanças no ambiente político-econômico nacional contemporâneo". In: Carleial, Liana \& V alLe, Rogério (O rgs.), Reestruturação produtiva e mercado de trabalho no Brasil, São Paulo: H ucitec/Abet, 1997. 
PIRES, Elson L. Silva. "Crise econômica, reestruturação produtiva e emprego: T ransformações nas montadoras da indústria automobilística no Brasil". In: Carleial, Liana \& Valle, Rogério (0 rgs.), Reestruturação produtiva e mercado de trabal ho no Brasil, São Paulo: H ucitec/Abet, 1997.

PO CH M AN N, M arcio. "M udança e continuidade na organização sindical brasileira no período recente". In: O LIVEIRA, Carlos A.B. \& M Aт Toso, Jorge E.L. (O rgs.), Crise e trabalho no Brasil. M odernidade ou volta ao passado? São Paulo: Scritta/Página Aberta/C esit, 1996.

PORT U GAL, M arcelo S. \& GARCIA, Lúcia S. "N otas sobre o desemprego estrutural no Brasil". In: Carleial, Liana \& Valle, Rogério (O rgs.), Reestruturação produtiva e mercado de trabalho no Brasil, São Paulo: H ucitec/Abet, 1997.

POST H U M A, Anne. Reestruturação e qualificação numa empresa de autopeças: U m passo aquém das intenções declaradas. Educação \& Sociedade, Campinas: Cedes/Papirus, 1993, no 45, p. 252-267.

QUADRO S, W aldir J osé. "A reestruturação das empresas e 0 emprego da classe média". In: O liveira, Carlos A.B. \& M attoso, Jorge E.L. (O rgs.), Crise e trabalho no Brasil. M odernidade ou volta ao passado? São Paulo: Scritta/Página Aberta/C esit, 1996.

RAM ALH O, José Ricardo. "As diversas faces da negociação no meio sindical brasileiro". In: M ARTINs, H eloisa de Souza \& (O rgs.), Tercerização: D iversidade e negociação no mundo do trabalho. São Paulo: H ucitec-C edi/N ETS, 1994.

RATT N ER, H enrique. "D ebate". In: Ferretti, Celso J. et al. (O rgs.), $\mathrm{N}$ ovas tecnol ogias, trabal ho e educação: U m debate multidisciplinar. Petrópolis: V ozes, 1994.

REIS, H.L. Implantação de programas de redução de desperdícios na indústria brasileira: U m estudo de caso. D issertação de M estrado. Coppead/UFRJ. Rio de Janeiro, 1994.

RELAT Ó RIO Anual da O CDE. T endências da Sindicalização. C apítuIo 4, 1992. 
RO D RIGUES, Iram Jácome. Trabalhadores, sindicalismo e democracia: A trajetória da CUT. T ese de D outoramento, USP. São Paulo, 1993.

ROSA, Cláudio Porto da. Tecnologia apropriada: U m conjunto homogêneo? Revista de Administração de Empresas. São Paulo, 1989, no 29 (1), p. 47-51.

RUAS, Roberto; ANTUNES, José A. \& ROESE, Mauro. "Avanços e impasses do modelo japonês no Brasil. O bservações acerca de casos empíricos". In: H IRATA, H elena (O rg.), Sobreo "modelo" japonês, São Paulo: Edusp, 1993.

RU BIN , I saak Illich. A teoria marxista do valor. São Paulo: Polis, 1987.

SALERN O, M ário Sérgio. "Produção, trabalho e participação: CCQ e Kanban numa nova imigração japonesa". In: Fleury, M aria T ereza Leme \& FISCHER, Rosa M aria. Processo e relações do trabalho no Brasil: M ovimento sindical, comissão de fábrica, gestão e partici pação, o modelo japonês de organização da produção no Brasil (CCQ e Kanban). São Paulo: Atlas, 1992.

. "M odelo japonês, trabal ho brasileiro". In: H IRATA, H elena (O rg.), Sobre o "modelo" japonês, São Paulo: Edusp, 1993.

. "Produção integrada e flexível e processo operatório: N otas sobre sindicatos e a formação profissional". Trabalho e Educação Coletânea CBE. 2ª ed. Campinas: Papirus, 1994.

SALM , Claudio. "D ebate". In: Ferrett।, C elso J. et al. (O rgs.), N ovas tecnologias, trabalho e educação: U m debate multidisciplinar. Petrópolis: Vozes, 1994a.

. "O s sindicatos, as transformações tecnológicas e a educação". Trabalho e Educação - Coletânea CBE. 2a ed. Campinas: Papirus, 1994b.

SALM , Claudio; SABÓ IA, João \& CARVALH O, Paulo G. "Produtividade na indústria brasileira: U ma contribuição ao debate". In: Carleial, Liana \& V alle, Rogério (O rgs.), Reetruturação produtiva e mercado de trabalho no Brasil. São Paulo: H ucitec/A bet, 1997. 
SANTOS, Anselmo L. dos \& POCH M AN N . "O custo do trabalho ea competitividade internacional". In: O LIVEIRA, Carlos A.B. \& M at Toso, Jorge E.L. (Orgs.), Crise e trabalho no Brasil. M odernidade ou volta ao passado? São Paulo: Scritta/Página Aberta/C esit, 1996.

SANTOS, Anselmo L. dos. "Encargos sociais e custo do trabalho no Brasil". In: O liveira, Carlos A.B. \& M attoso, Jorge E.L. (O rgs.), Crise e trabalho no Brasil. M odernidade ou volta ao passado? São Paulo: Scritta/Página Aberta/C esit, 1996.

SILVA, Elizabeth Bortolaia. "Refazendo a fábrica fordista? T ecnologia e relações industriais no Brasil no final da década de 1980". In: H IRATA, H elena (O rg.), Sobre o "modelo" japonês, São Paulo: Edusp, 1993.

SIN D ICAT OS declinantes, bem ou mal para a sociedade. Gazeta M ercantil, 5 jul. 1995.

"TERCEIRA revolução industrial começa no Rio", diz López. Folha de S. Paulo, 15 out. 1995, p. 2-5.

TU M O LO, Paulo Sérgio. "T rabalho: Categoria sociológica chave e/ou princípio educativo? 0 trabalho como princípio educativo diante da crise da sociedade do trabal ho". Perspectiva - Trabalho e educação: U m olhar multirreferencial. Florianópolis: CED/U FSC, 1996, vol. 14, no 26, p. 39-70.

. M etamorfoses no mundo do trabal ho: Revisão de algumas linhas de análise. Educação \& Sociedade, C ampinas: Cedes/Papirus, 1997a, no 59, p. 333-350.

. 0 novo padrão de acumulação de capital e a formação sindical da Central Ú nica dos Trabalhadores. T rabalho apresentado na $20^{2}$ Reunião Anual da Anped, 1997b.

.D a subsunção formal do trabalho à subsunção real da vida social ao capital: A pontamentos de interpretação do capitalismo contemporâneo. T rabalho apresentado na 24 ${ }^{\text {a }}$ Reunião Anual da Anped, 2000.

. 0 significado do trabalho no capitalismo e o trabal ho como princípio educativo: Ensaio de análise crítica. Texto apresentado na 25ª Reunião Anual da Anped, 2001. 
VIDAL, M anuel Cereceda. "M odernización sindical para un nuevo escenario económico". In: CASTRo, M aria S.P. \& Wachendorfer, Achim (Coords.), Sindicalismo latinoamericano. Entrela renovación y la resignación. Caracas: N ueva Sociedad/ILDES-FES (Brasil), 1995.

W ACHEN D O RFER, Achim. "El sindicalismo latinoamericano: Salud delicada, pronóstico reservado". In: CASTRO, M aria S.P. \& Wachendorfer, Achim (Coords.), Sindicalismo latinoamericano. Entre la renovación y la resignación. Caracas: N ueva Sociedad/ ILDES-FES (Brasil), 1995. 